\title{
A Study of Spatial Evolution Patterns of Tourist Destinations Disaster Risks
}

\author{
Yingyue Sun ${ }^{1,2}$, Qingshan Yang ${ }^{2}$, Peng Chen ${ }^{1}$ \\ 1. College of Tourism and Geographical Sciences, Jilin Normal University, Siping 136000, China \\ E-Mail: syy800201@126.com;pp11290@163.com. \\ 2. College of Geography, Northeast Normal University, Changchun 130024, China \\ E-Mail: yangqs027@nenu.edu.cn.
}

Received December 31, 2017

Accepted January 25, 2018

\begin{abstract}
Due to the strong suddenness, large destruction and wide impact, disasters can cause serious property and safety loss to tourists, damage significantly tourism infrastructure, properties and resources. In order to prevent disaster and to better understand future disaster risk evolution, we have built a comprehensive disaster risk evaluation model using selected 17 economic and social indicators from tourist destinations in Jilin Province based on the four-factor theory of natural disaster risk formation. The model was used to assess tourist destination disaster risk in Jilin Province for the period of 2009 - 2014. Using GIS technology, we have developed a tourist destination disaster risk zoning map of $2009-2014$ for Jilin Province, classified the spatial evolution patterns of tourist destination disaster risk. Results showed that the increases in tourist destination disaster risks in Jilin may be spatially evolved by edge contact, sudden internal elevation, swinging and leaping; the decreases in tourist destination disaster risks may be spatially evolved by edge recession, sudden internal reduction and contiguous reduction. The disaster risk spatial evolution model is of value for the emergency department of Jilin Province to take specific emergency measures according to a particular pattern.
\end{abstract}

Keywords: Tourist Destination; disaster risks; spatial evolution

Accompanying global climate change, there is an increasing propensity in disaster frequency, intensity and scope of impact. Because the tourism industry is highly sensitive to disaster strikes, a disaster incidence may result in negative changes in the tourism industry or the dependent industries, and causes tourism concussion. Therefore, the tourism industry is the hardest-hit sector in the economy by disaster strikes(Pei Wei,2010). The disaster risk in a tourism destination is the prediction of the future danger. Disaster risk assessment based on scientific and technological support is needed for tourism infrastructure planning, construction and zoning. Therefore, it is necessary to investigate systematically tourist destination disaster risks.

\section{Tourist Destination Disaster Risk Definition and Research Development}

There are many definitions for the tem "disaster risk". Maskrey defined disaster risk as the total loss caused by a natural disaster incidence(Makrey A1989). Smith defined it as the occurrence probability of a disaster strike(smith $\mathrm{K}, 1996)$. Tobin defined it as the occurrence probability multiplied by the expected loss(Tobin G A,1997). Deyle defined it as the occurrence probability combined with the disaster consequence magnitude(Deyle R E,1998). Hurst defined it as the description of the probability and outcomes(Hurst N W,1998). In order to quantifydisaster risks, many scholars have proposed various methods. Common methods are the following: (1) Risk $=$ Hazard + Vulnerability (Maskrey, 1989); (2) Risk = Probability $\times$ Loss (Smith, 1996); (3) Risk = Probability +Vulnerability

Copyright (C) 2018, the Authors. Published by Atlantis Press.

This is an open access article under the CC BY-NC license (http://creativecommons.org/licenses/by-nc/4.0/). 
(Tobin, Montz, 1997 Nian); (4) Risk) = Hazard $\times$ Consequence) (Deyl, Hurst, 1998); (5) Risk $=$ Hazard $\times$ Vulnerability $\times$ Exposure $\times$ Emergency response and recovery capability (ZhangJiquan,2007). Among these five methods, the first four are similar, and the calculated risk size is a fixed value. For a given area, only a final risk value is obtained using the first four methods. It is hard to tell as to what give rise to the risk magnitude in the given area. The fifth method is comprehensive in risk quantification. Through the weighted calculation of the four contributing factors, not only the size of the disaster risk can be determined for a study area, but also how much each factor contributed to the final risk extent. Therefore, based on the definition of above, this paper used the following comprehensive definition for the disaster risk of a tourism destination: the risk extent of disaster strikes and probability of occurrence in the next few years are determined by the hazard $(H)$, exposure $(E)$, vulnerability $(\mathrm{V})$ and disaster prevention and recovery capacity (R) combined.

Research in China about tourist destination disaster risks started late, and more studies were qualitative rather than quantitative. As the International Tourism Association and the World Tourism Organization recognized the importance of disaster risks, many domestic scholars began to study the issue. Liu et al (Liu Haolong, 20017) selected eight assessment indicators based on the magnitude of hazards, vulnerability of tourism resources and the capability of prevention and recovery, established a comprehensive evaluation model of disaster risks for eight scenic tourist resources in Inner Mongolia. Luo et al(Luo Zhenjun,2008) analyzed the major risk factors and mechanism of disasters in tourist attractions based on the tourists themselves, resort management and comprehensive social factors. Yuan et al(Yuan Hong,2003) discussed in detail from natural, social and development aspects about the disaster risk management characteristics and measures in tourist destinations. Zhao et al (Zhao Liming,2010) evaluated disaster risks according the frequency and destruction of disasters, assessed the system vulnerability from tourists, tourism resources, ecological environment and economy aspects, and assessed prevention and rescue capacity based on early warning, rescue and recovery capacity. Xi et al (XI Jianchao,2007)established a tourism risk assessment model from 14 selected assessment indicators of seven aspects, including traffic, security, health, accommodation, weather, tour route, medical rescue.

The above studies were mainly about the tourist destination risk definition and quantification methods regarding the magnitude of danger, the exposure and vulnerability of the hazard bearing body. According to the above definitions and quantification methods, we can see that all have a certain one-sidedness. Considered from a comprehensive point of view, tourist destination disaster risks have both natural attributes and social attributes. In addition to the above three aspects, disaster prevention and recovery capability must also be added to the tourism disaster risk (assessment). As such, the mechanism (comprehensive assessment scheme?) of tourism disaster risks is formed.

Tourist destination disaster risk refers to the degree to which disaster damages may reach in the next few years and its probability of occurrence. In other words, tourism disaster risk is determined comprehensively by hazards, the exposure and vulnerability of the hazard bearing body, prevention and mitigation capacity. (Fig1). The tourist disaster risk cane be expressed mathematical below:

Disaster risk $=$ hazard $(\mathrm{H}) \times$ exposure $(\mathrm{E}) \times$ Vulnerability $(\mathrm{V}) \times$ disaster prevention and mitigation capacity $(\mathrm{R})-1$

Risk refers to the degree of disaster abnormality in a tourism destination. It is mainly determined by the frequency and intensity of hazards of various activities. The greater the intensity and the greater the strength, the greater the risk is. Exposure refers to all factors threatened disasters, including all tourism resources, infrastructure, and other visitors. The more tourism resources, infrastructure, and tourists exposed to a disaster, the greater the exposure is. Vulnerability refers to the internal damages or loss of a given tourist destination, tourism resources, infrastructure, tourists in response to the disaster. The greater degree of the damage or loss, the greater the vulnerability of the disaster bearing bodies. The response and recovery capacity indicate the degree of short term or the long term inherent ability to recover from a disaster strike. The higher the recovery capacity in a tourist destination, the less the disaster losses and the extent of impact. 


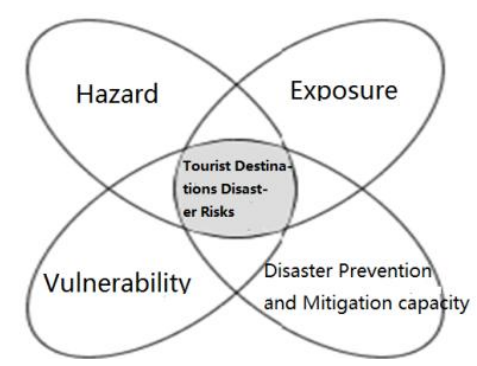

Fig 1. Mechanism of disaster risk formation in tourist destination

\section{Study Area}

Jilin Province is located in the heart of northeast China $\left(40^{\circ} 51^{\prime}-46^{\circ} 18^{\prime} \mathrm{N}, 121^{\circ} 38^{\prime}-131^{\circ} 17^{\prime} \mathrm{E}\right)$ (Fig1)., with a south to north width of $600 \mathrm{~km}$, east to west about 750 $\mathrm{km}$. The province suffers from many types of frequent natural disasters (floods, earthquakes, fires, low temperature, and cold hazards). These disasters have a great impact on the tourism industry in Jilin Province. The main tourism resources in the province include Changbai Mountains (5A-class National tourist attractions), Jilin Rime, the Century Movie City, Jilin Songhua Lake, Koguryo Kingdom Cultural Site, Moon Lake, Changchun Puppet Palace and many other natural and cultural sites. The province is a famous tourist destination due to its natural and cultural tourist attractions.

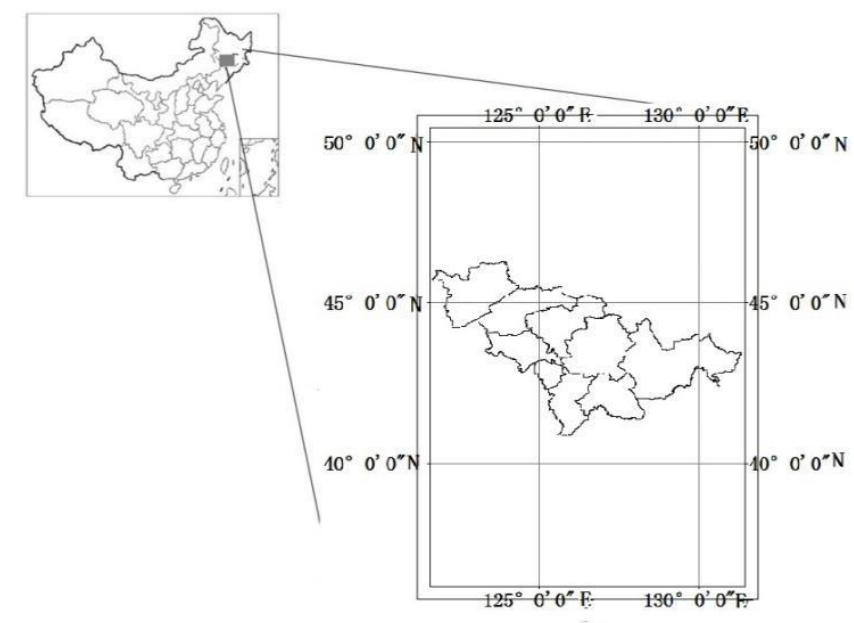

Fig 2 the study area

\section{Research Methods and Data Sources}

\subsection{Research Methods}

\subsubsection{Natural Disaster Risk Index}

Natural disaster risks refer to the possibility of a disaster incidence and the extent to which the disaster damage could reach in the next period of time. Generally, the risk is the combined effects of hazards, the bearing body exposure, bearing body vulnerability, and the response and recovery ability (Zhang Jiquan,2007). The above four factors are indispensable in the formation of natural disaster risk. The risk index can be expressed as:

Natural Disaster Risk Index

$=$ Hazard $\times$ Vulnerability $\times$ Exposure $\times$ Recovery capacity

\subsubsection{Grid GIS Technology}

The grid GIS technology is an interdisciplinary field of the existing grid technology, spatial information technologies and geographical information technology. It is an application of GIS technology in a grid environment (Liu Haolong,2007). Currently, there are two types of grids, namely the regular grid technology and irregular grid technology. The grid size (accuracy) and style are flexible, determined by the contents. Contemporary small-scale studies commonly use this method. In this paper, the city of Jilin is divided into 3260 squares using regular grids, $5 \mathrm{KM} \times 5 \mathrm{KM}$ per square. The travel disaster risks were evaluated for each square. This approach improved the spatial resolution and reasonableness of the risk assessment.

\subsubsection{Weighted Comprehensive Assessment}

The weighted comprehensive evaluation method assumes that due to the difference in the quantified value of indicator $\mathrm{i}$, and each indicator $i$ has a different impact on the specific factor $j$, the formula is:

$$
C V_{i}=\sum_{i=1}^{m} Q V_{i j} W C_{i} .
$$

Where, $\mathrm{CV}_{\mathrm{i}}$ is the total value of the factor being evaluated; $Q V_{i j}$ is the ith indicator for factor $\mathrm{j}\left(Q V_{i j} \geq 0\right)$; $\mathrm{WC}_{\mathrm{i}}$ is the 
weight value of index $i\left(0 \leq W C_{i} \leq 1\right)$, calculated with the AHP method. The number of evaluated indicators is $\mathrm{m}$.

\subsection{Data Sources}

The meteorological data were collected from the meteorological department of Jilin Province. Terrain data and vector data for the study area were collected from the Earth System Science Data Sharing Network STRM system (90 m spatial resolution). Socio-economic data were from the "Jilin Provincial Statistical Yearbook," tourism statistics, conservation plans and tourism development plans in the local nature reserves, Jilin tourism master plan, Jilin and natural reserve list, and demographic data.

\section{Tourist Destination Disaster Risk Evaluation System, Model Construction and Risk Zoning}

\subsection{Index System}

Jilin Province is one of the provinces of frequent disaster strikes. Major disasters include floods, droughts, earthquakes, landslides and mud flows. These disasters have a large impact on the tourism industry. In a short period of time, a disaster strike can lead to casualties, destruction of tourism infrastructure and resources.
Therefore, indicators were selected based on the disasterinduction process and the magnitude of impact on tourism, the frequency and magnitude of damages by a disaster strikes, environment geological structure, topography, climate, disaster trends, vegetation, water and human activities. Selected indicators should be scientific, simple, actionable, representative (Luo Zhenjun,2008; Yuan Hong,2003). Following the above principles, 17 indicators were selected (Table 1).

\subsection{Evaluation Model}

According to the mathematical formulas, combined with the tourism disaster risk evaluation system, using a weighted comprehensive evaluation method, the tourism disaster risk assessment model was established(Zhao Liming,2010; XI Jianchao,2007):

$$
\begin{gathered}
L D R I=\left(H^{W H}\right)\left(E^{W E}\right)\left(V^{W V}\right)\left(1-R^{W R}\right) \\
H=W_{H 1} X_{H 1}+W_{H 2} X_{H 2}+W_{H 3} X_{H 3} \\
E=W_{E 1} X_{E 1}+W_{E 2} X_{E 2}+W_{E 3} X_{E 3}+W_{E 4} X_{E 4} \\
V=W_{V 1} X_{V 1}+W_{V 2} X_{V 2}+W_{V 3} X_{V 3}+W_{V 4} X_{V 4}+W_{V 5} X_{V 5}
\end{gathered}
$$

\begin{tabular}{|c|c|c|c|}
\hline Primary & Secondary & Tertiary & Weight \\
\hline \multirow[t]{3}{*}{ Hazard } & Disaster frequency & $\mathrm{X}_{\mathrm{H} 1}$ historical disaster frequency & 0.079 \\
\hline & destructiveness & $\mathrm{X}_{\mathrm{H} 2}$ number of tourist affected & 0.119 \\
\hline & & $\mathrm{X}_{\mathrm{H} 3}$ economical loss & 0.053 \\
\hline \multirow{4}{*}{ Exposure } & Resource exposure & $\mathrm{X}_{\mathrm{E} 1}$ amount of resources & 0.071 \\
\hline & & $\mathrm{X}_{\mathrm{E} 2}$ completeness of facility & 0.050 \\
\hline & Life exposure & $\mathrm{X}_{\mathrm{E} 3}$ annual number of visitors & 0.055 \\
\hline & Financial exposure & $\mathrm{X}_{\mathrm{E} 4}$ tourism income & 0.071 \\
\hline \multirow{5}{*}{ Vulnerability } & Resource vulnerability & $\mathrm{X}_{\mathrm{V} 1}$ number of national attractions & 0.045 \\
\hline & & $\mathrm{X}_{\mathrm{V} 2}$ number of national reservations & 0.048 \\
\hline & & $\mathrm{X}_{\mathrm{V} 3}$ completeness of facility & 0.060 \\
\hline & Life vulnerability & $\mathrm{X}_{\mathrm{V} 4}$ age ratio of visitors & 0.045 \\
\hline & Economyvulnerability & $\mathrm{X}_{\mathrm{V} 5}$ tourism GDP contribution & 0.051 \\
\hline \multirow[t]{5}{*}{ Recovercapacity } & Evacuation & $\mathrm{X}_{\mathrm{R} 1}$ accessibility & 0.051 \\
\hline & & $\mathrm{X}_{\mathrm{R} 2}$ number of shelters & 0.037 \\
\hline & & $\mathrm{X}_{\mathrm{R} 3}$ rescue ability & 0.053 \\
\hline & Recovery ability & $\mathrm{X}_{\mathrm{R} 4}$ insurance completeness & 0.053 \\
\hline & & $\mathrm{X}_{\mathrm{R} 5}$ number of hospital beds & 0.057 \\
\hline
\end{tabular}

Table 1: Tourist destination disaster risk evaluation indicator system 
$\mathrm{R}$ values were the hazard, exposure, vulnerability, disaster recovery index, respectively. $x_{i}$ in equations (2) - (6) was the value of each indicator, $\mathrm{W}_{\mathrm{i}}$ is the weight value of each indicator, where the weight of the indicator was calculated using AHP method (Zhang,2007).

\subsection{Tourism Hazard Risk Assessment}

Equations (6) - (9) were used to calculate the risk, exposure, vulnerability, recovery capacity values of each tourism disaster factor. The natural breaking points were used for grade assignment for all samples. Jilin tourist destinations were graded as low risk, sub-low risk, medium risk, sub-high risk and high risk, respectively. These indices were assigned to GIS grid (Chen Peng,2014; Sun Yingyue,2016), produced the Jilin Province 20092014 tourist disaster risk level zoning map (Fig 2). Based on the historical disaster and field investigation in jilin province, the evaluation classification standard of tourism destination security risk assessment is divided into five grades according to the natural fracture method. The classification standard is shown in the table below

(Table 2).

Table 2 Evaluation result classification standard

\begin{tabular}{|c|c|c|c|c|c|}
\hline Designation & & Classifi & andard & & \\
\hline velue & $0 \sim 0.125$ & $0.125 \sim 0.365$ & $0.365 \sim 0.489$ & $0.489 \sim 0.511$ & $0.511 \sim 0.782$ \\
\hline Rating & Low Risk & Lower Risk & Medium Risk & Higher Risk & Higher Risk \\
\hline
\end{tabular}
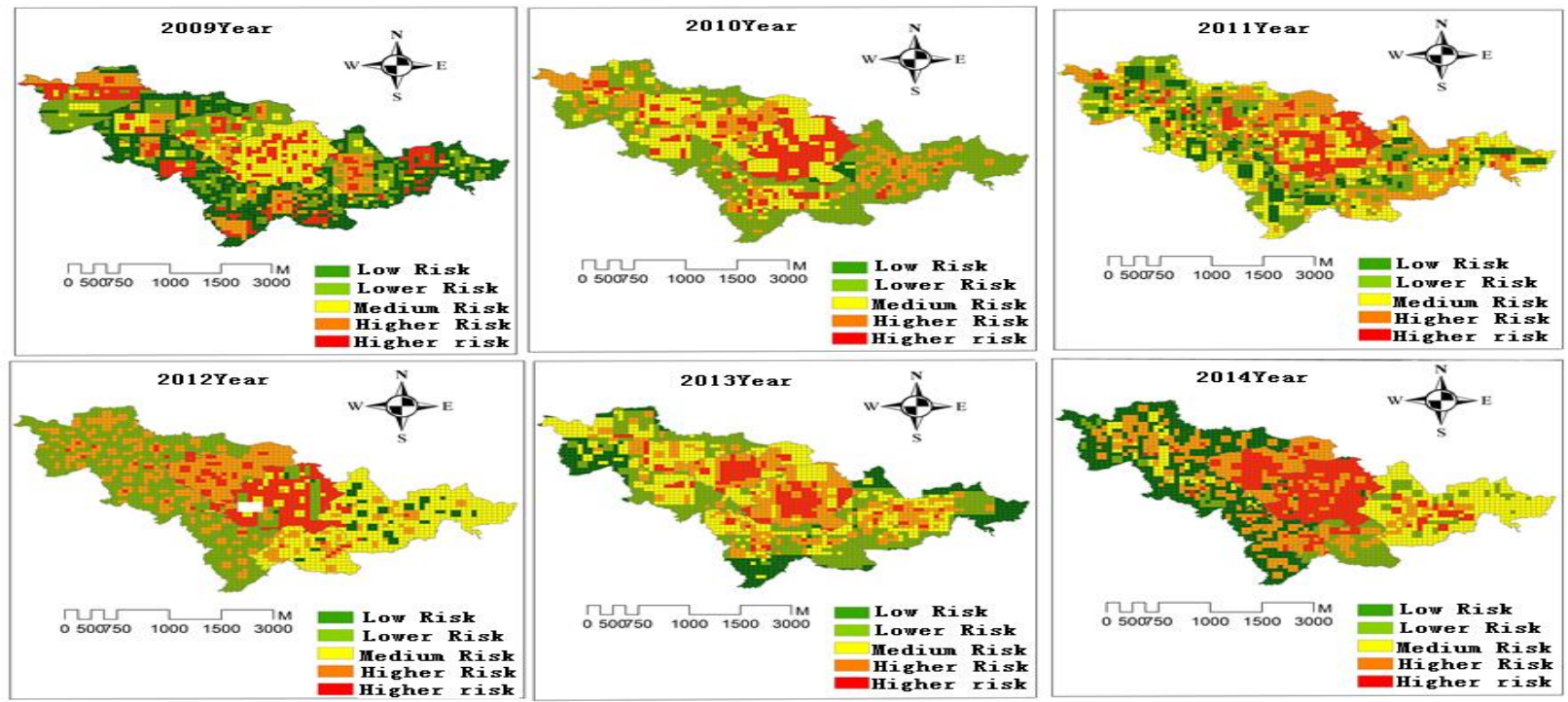

Fig2. Disaster Risk of Jilin Tourism Resources 2009-2014

\subsection{Evaluation Result Verification}

According to statistical yearbook from 2009 to 2014 in jilin province,the location and scope of the security incidents that threaten the tourist destination are sorted out and analyzed. It is found that there are more frequient security incidents in central jilin province,the frequency of security incidents in south and northeast Jilin province are lower than central Jilin province,and there are less frequent security incidents in westeast Jilin province. the result is consistent with the study, so the results of the study can be used to evaluate the safety risk of tourism.

\section{Spatial Evolution Patterns of Disaster Risk in Tourism Resources}

Based on the above findings, using the ARCGIS spatial analysis function, we analyzed the 6-year (2009 - 2014) spatial change process in Jilin Province, including tourism 
disaster risk pattern changes between any two years. The results are summarized, obtained the spatial patterns of risk changes in Jilin. We proposed two tourist disaster risk spatial evolution modes: One is the risk increasing mode containing edge contact, swing, and sudden internal elevation and leaping patterns; the other is the risk decreasing mode, including the edge retreating, contiguous reduction and internal decreasing patterns (Table3).

Table 3: Tourist destination disaster risk spatial evaluation patterns

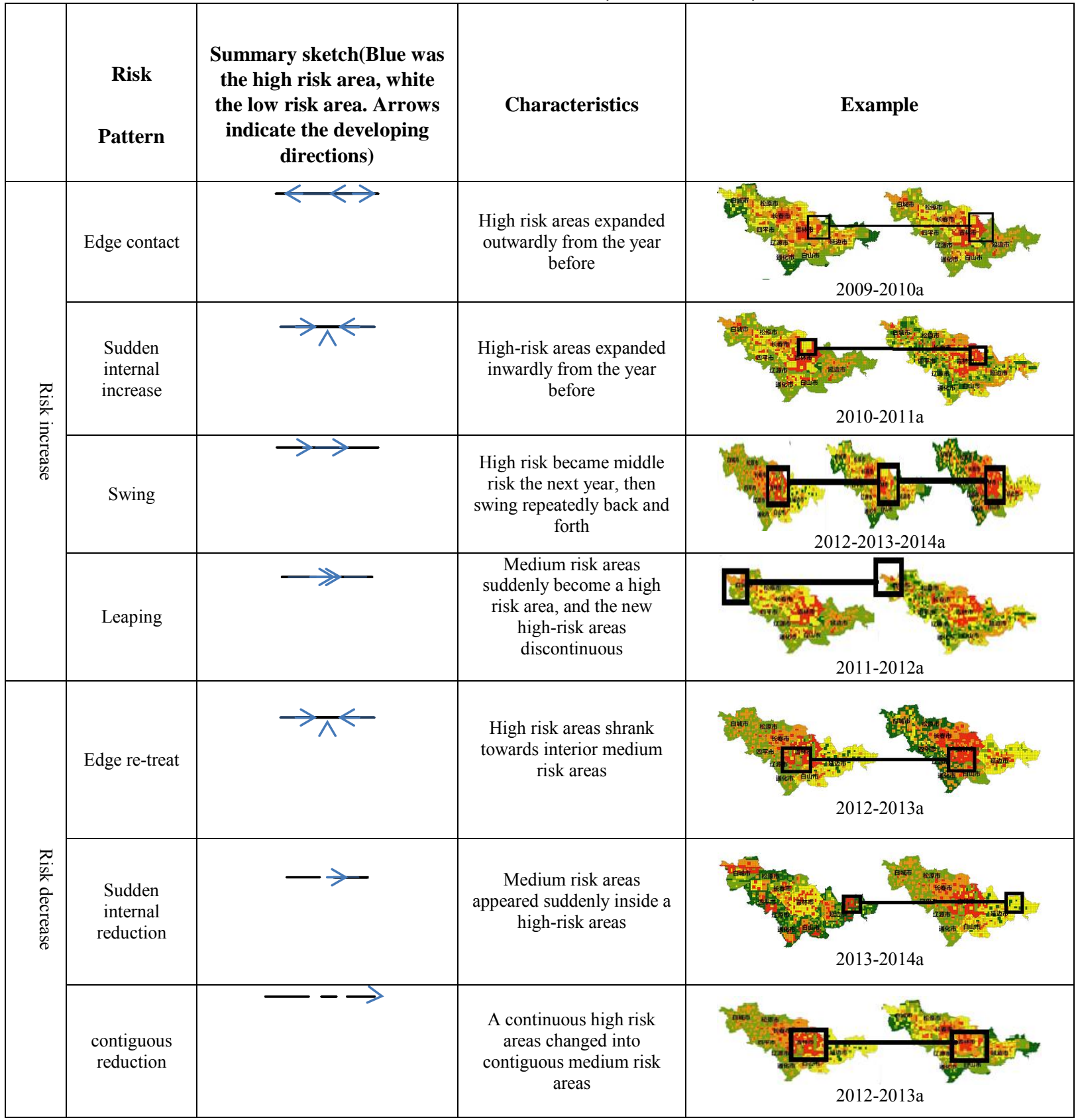


In the risk increasing mode, the edge-contact pattern is more obvious for 2009-2010, appeared in the eastern part of Jilin. The main reason for this pattern was that under the same disaster developing environment, the increase in hazard bearing body caused the elevation in the tourism disaster risk. The internal elevation pattern appeared in 2010 - the 2011. The main cause of this pattern was the changes in southern Jilin where the disaster development environment and the hazard bearing body changed: the tourism infrastructure, resources were gradually increased, eventually led to an internal sudden increase in the tourism disaster risk. The swinging and leaping patterns occurred mainly in Jilin City. Due to an increase in tourism resources, the number of tourists and tourism infrastructure, the tourism disaster risk was increased, but the next year due to the increase in disaster prevention and recovery capacity, the tourism disaster risk became smaller; Baicheng City increased investment in the recent years in urban construction, tourism facility construction, resulting in increased exposure and vulnerability of the hazard bearing body, thus resulting in an increasing trend in disaster risks in two years, but not sustained. In 2011-2014, due to the increasing disaster prevention and recovery capabilities, the disaster risk of the tourist destinations was reduced in recent years. The disaster risk reduction transfer patterns include edge retreating, contiguous reduction and internal sudden reduction. Among the three patterns, the cause for flooding risk reduction was similar. Due to little change in the disaster developing environment, a relatively stable disaster bearing body, but an increasing government disaster prevention and recovery capacity, the overall tourist destination disaster risks showed a trend where central Jilin Province tended to increase, while other areas tended to decrease. The above disaster risk patterns changed year by year, as a result of changes in disaster developing environment, hazard bearing body and disaster prevention and recovery capacity.

In summary, the tourism disaster risk changes can reflect the condition of disaster developing environment, the hazard bearing body and disaster prevention and recovery capabilities from year to year in the study area. These results provide the basis for decision making in tourism emergency management departments to take different emergency measures in different years. These results also provide a reference for monitoring tourism disaster risk transfer patterns.

\section{Conclusion}

In this study, we have built a comprehensive tourism disaster risk assessment model using a grid in which a unit square was $5 \mathrm{KM} \times 5 \mathrm{KM}$ in size, utilizing the natural disaster index method, AHP and GIS technology. We evaluated tourist destination disaster risks in Jilin Province, and produced the Jilin Province 2009- 2014 grid scale tourist destination disaster risk zoning map, and analyzed and classified Jilin tourism disaster risk spatial evolution patterns. The tourism disaster risk increasing patterns included edge contact, sudden internal elevation, swinging and leaping. The tourism disaster risk reduction patterns included edge retreat, sudden internal reduction, and contiguous reduction. By induction and analysis, we identified the causes of tourism disaster risk changes. These results can provide basis for tourism emergency management departments to make different decisions in different years, and also provide a reference for understanding tourist destination disaster risks.

\section{Acknowledgments}

By the National Natural Science Fund (41501557, 41371495, 41501559); Jilin Province Science and Technology Department of youth fund $20150520081 \mathrm{JH}$.

\section{References}

Pei W. Research on the appraisals and countermeasures of the disaster risks of Sichuan tourism places evoked by the earthquake. Soft Science,2010, 24(4):89-93.

Makrey A. Disaster Mitigation: A Community Based Approach. Oxford: 1989.

smith K. Environmental Hazards: Assessing Risk and Reducing Disaster. New York: Routledge, 1996.

Tobin G A, Montz B E. Natural Hazards: Exp lanation and Inte-gration. New York: The Guilford Press, 1997.

Deyle R E, French S P, Olshansky R B. Hazard assessment: the factual basis for planning and mitigation. Burby R J. (ed.): Cooperation with Nature: ConfrontingNatural Hazardswith Land -Use Planning for Sustainable Communities. Washington D C: Jo-seph Henry Press, 1998.116-119.

Hurst N W. Risk assessment: the human dimension. Cambridge: The Royal Society of Chemistry, 1998. 
Zhang J Q, Li N. Quantitative methods and Applications of Risk Assessment and Management on Main Meteorological Disasters. Beijing: Beijing Normal University Publishing House, 2007.

Liu H L, Ge Q S, Xi J C. Disaster risks assessment of regional tourism resources: a case study of Inner Mongolia Keshiketeng Banner. Resources Science, 2007, 29(1):118124.

Luo Z J, Tong R P. Analysis on safety capacity and assessment of accident risk in tourism spots. China Safety Science Journal, 2008,18(2):150-156.

Yuan H. On disaster risk management of tourism destination in Southwest China. Journal of Chongqing University of Posts and Tclccommunications, 2003, 10(6):15-17.

Zhao L M, Liu H Y. Assessment of tourism systems ecological disaster risk based on fuzzy matter-element. Journal of Arid Land Resources and Environment, 2010, 10(24): 186-188.
Xi J C, Liu H O, Qi C B,Wu P. The risk assessment model of tourism destination-taking ten adventure tourism lines as a case study. Journal Of Mountain Science, 2007, 25(3):370375.

Zhang J Q, Liu X P,Tong Z J. The study of grassland fire disaster risk assessment and regionalization: A case study in the western Jilin Province. Geographical Research, 2007, 26(4):755-761.

Zhang J Q, Liang J D, Zhou D W. Risk assessment of ecological disasters in Jilin Province based on GIS. Chinese Journal of App lied Ecology, 2007,18(8):1765-1770.

Chen P, Zhang L F, Sun Y Y. Based on the GIS grid scale urban rainstorm waterlogging disaster risk assessment. Journal of Zhejiang Agricultural Sciences 2014,1(10):1610-1615.

Sun Y Y, Chen P, Zheng L F. Risk assessment of regional tourism resource disaster of two kinds of spatial scale. Hubei Agricultural Sciences,2016,66(7):1862-1866. 